\section{Phenotypic variation and heritability of heading date in hexaploid oat}

\author{
Gustavo Mazurkievicz ${ }^{1}$, Itacir de Pierri Ubert ${ }^{1}$, Felipe Augusto \\ Krause $^{1}$ and Itamar Cristiano Nava ${ }^{1 *}$
}

\begin{abstract}
The onset of flowering is decisive to the reproductive success of plants. The objectives of this study were to characterize the phenotypic variation in heading date and estimate its heritability in segregating populations of oat (Avena sativa L.). $F_{2}$ and $F_{3}$ generations of two large populations, derived from crosses 'URS Taura $\times$ Leggett' and 'FLO206B-S-B-S1 $\times$ UFRGS 078030-1', were evaluated. $A$ wide phenotypic variation in the number of days to heading was observed in both populations. Heritability coefficients of 0.68 and 0.46 were estimated for the 'URS Taura $\times$ Leggett' and 'FLO206B-S-B-S1 x UFRGS 078030$1^{\prime}$ populations. Our results demonstrate that genetic differences derived from parents in response to photoperiod and temperature explain most of the phenotypic variation in heading date of oat populations. Understanding genetic and environmental effects on flowering expression is essential to increase the response to selection for well-adapted and high-yielding oat cultivars.
\end{abstract}

Keywords: Avena sativa L., photoperiod, temperature, vernalization, adaptation.

\section{INTRODUCTION}

Cultivated oat (Avena sativa L.) is grown in an area of over 10 million hectares, and roughly 26 million tons of grains are harvested annually around the world (FAOSTAT 2019). The cultivation of oat in many countries is intended to provide grains for human consumption and animal feed. The adaptation of oats to a specific growth area is directly associated with the ability of plants to synchronize the onset of flowering with the appropriate environmental conditions for reproduction. The transition from the vegetative phase to the reproductive phase in oats occurs in response to photoperiod, temperature, and vernalization. Oat is a long-day crop in which earlier flowering is promoted under longer photoperiods in many genotypes (Sorrells and Simmons 1992). Oat genotypes also vary in their response to vernalization, and both spring and winter forms of $A$. sativa exist worldwide (Nava et al. 2012).

\begin{abstract}
Although environmental stimuli that influence flowering time are known, genetic and molecular factors that affect the expression of this trait are poorly understood in oats compared to other cereal crops. In wheat (Triticum spp.) and barley (Hordeum vulgare L.), the occurrence of flowering depends on the coordinated expression of genes in different metabolic pathways, including photoperiod, vernalization, temperature, and earliness per se (Würschum et al. 2018). The Ppd-1 (Photoperiod-1) and Ppd-H1 genes regulate the sensitivity to photoperiod in wheat and barley, respectively (Nishida et al. 2013, Pearce et al.
\end{abstract}

Crop Breeding and Applied Biotechnology 19(4), 436-443, 2019 Brazilian Society of Plant Breeding. Printed in Brazil http://dx.doi.org/10.1590/198470332019v19n4a61

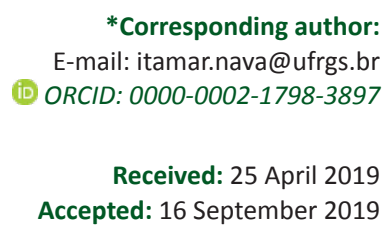

${ }^{1}$ Universidade Federal do Rio Grande do Sul, Departamento de Plantas de Lavoura, Av. Bento Gonçalves, 7712, 91.540-000, Porto Alegre, RS, Brazil 
2017). Vernalization response is controlled by the Vrn1 (Vernalization 1), Vrn2 (Vernalization 2), Vrn3 (Vernalization 3), and Vrn-D4 (Vernalization-D4) genes (Kippes et al. 2016). Temperature sensitivity is mainly regulated by a special class of transcription factors coded by the PIF (PHYTOCHROME INTERACTING FACTOR) gene family (Capovilla et al. 2014). Earliness per se is associated with genes that have an expression pattern regulated by the circadian clock, such as the ELF3 (EARLY FLOWERING 3) gene (Zikhali et al. 2016).

The development of molecular and genomic strategies over the last decades has contributed to a more comprehensive exploitation of the genetic mechanisms that influence important agronomic traits in oats, including flowering time. Quantitative trait loci (QTL) associated with early flowering and the vernalization response of different oat mapping populations have been reported (Locatelli et al. 2006, Nava et al. 2012). Oat sequences with high molecular identity to the $V r n 1$ and $V r n 3$ genes were cloned, and a copy of the $V r n 3$ gene was mapped in collinear chromosomal regions in the Kanota $\times$ Ogle, UFRGS $8 \times$ UFRGS 930605, and UFRGS $881971 \times$ Pc68/5*Starter mapping populations (Nava et al. 2012). Recently, a genome-wide association study revealed the accurate identification of genomic regions associated with heading date in oats (Klos et al. 2016). These regions were located on linkage groups Mrg11, Mrg20, and Mrg21 in the oat map reported by Chaffin et al. (2016).

Despite the significant progress achieved with flowering time in oats, much research is still needed before the breeding of this important adaptive and agronomic trait can be based on solid scientific grounds. The development of advanced models that integrate genetic and environmental factors will be essential for a better understanding and rational use of the phenotypic variation observed for the flowering time in hexaploid oats. In this context, a fundamental aspect in plant breeding is to estimate the fraction of the total variance among plants of a population that may be attributed to genetic differences between them. This ratio is called heritability, which is one of the most important components of the breeder's equation that aims to predict the expected response to selection. In general, the greater the heritability of a trait, the greater the expected genetic gain since artificial selection can be carried out more efficiently. The objectives of this study were to characterize the phenotypic variation in heading date and estimate its heritability in segregating populations of hexaploid oat (Avena sativa L.).

\section{MATERIAL AND METHODS}

\section{Oat populations}

Two oat populations at the $F_{2}$ and $F_{3}$ generations were evaluated in this study. The segregating populations were derived from the crosses URS Taura $\times$ Leggett and FL0206B-S-B-S1 $\times$ UFRGS 078030-1. The parents of each population were chosen based on their phenotypic differences in flowering time. The early-flowering parents URS Taura (UFRGS

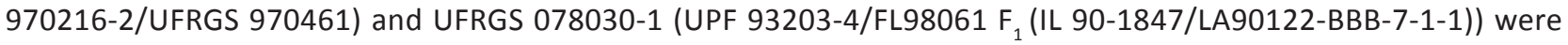
developed at the Federal University of Rio Grande do Sul (UFRGS), Brazil. The late-flowering parent FL0206B-S-B-S1 (UFRGS 995088-3/LA9535D118-4) was developed at the University of Florida, Gainesville, FL, USA. The super lateflowering parent Leggett (OT294/Pc94) was developed at the Agriculture and Agri-Food Canada, Cereal Research Centre, Winnipeg, MD, Canada. The parents' phenotypes described above correspond to differences in flowering time under field conditions in Southern Brazil.

\section{Phenotypic variation in heading date}

Parents and segregating populations from the crosses URS Taura $\times$ Leggett and FL0206B-S-B-S1 $\times$ UFRGS 078030-1 were included in experiments designed to measure differences in heading date in hexaploid oat. The experiments were carried out at the UFRGS Agronomy Experimental Station, located in Eldorado do Sul, Brazil. From the crosses URS Taura $\times$ Leggett and FL0206B-S-B-S1 $\times$ UFRGS 078030-1, 563 and 733 plants at the $F_{2}$ generation were evaluated, respectively. Both populations were seeded on June 20, 2015, with individual seeds distributed in $3 \mathrm{~m}$ long rows in the field with a spacing of $0.10 \mathrm{~m}$ between seeds and $0.30 \mathrm{~m}$ between rows in a no-tillage system (with soybean as the preceding crop). Of the two crosses, 74 and 87 families in the $F_{3}$ generation were evaluated. Both populations were seeded on June 14, 2016, with individual seeds of each family distributed in $1 \mathrm{~m}$ long rows in the field with a spacing of $0.10 \mathrm{~m}$ between seeds and $0.30 \mathrm{~m}$ between rows in a no-tillage system (with soybean as the preceding crop). Minimum and maximum daily temperature, day length, and rainfall were used to quantify environmental variation in 2015 and 2016. 


\section{G Mazurkievicz et al.}

The environmental data were obtained from the National Institute of Meteorology (INMET) (www.inmet.gov.br/projetos/ rede/pesquisa). The heading date, estimated as the number of days from emergence to heading, was recorded as the approximate time of panicle appearance at the $55^{\text {th }}$ stage of the Zadoks' scale. At the $F_{3}$ generation, single plants within each family were evaluated and the phenotypic data were used to estimate the average number of days to heading of each family. The variation in the number of days from emergence to heading among $F_{2}$ individuals and the average number of days to heading among $\mathrm{F}_{3}$ families were analyzed through the frequency distribution of both populations.

\section{Heritability of the heading date}

The heritability analysis of the heading date was carried out by the parent-offspring regression method in the oat populations URS Taura $\times$ Leggett and FL0206B-S-B-S1 $\times$ UFRGS 078030-1. The linear regression coefficient $(b)$ was used to estimate the heritability ( $h$ ), as reported by Falconer and Mackay (1996). Phenotypic data were obtained from the number of days from emergence to heading of the $F_{2}$ individual (parent), and the average number of days from emergence to heading of its $F_{3}$ family (offspring). As the $F_{3}$ family was generated from the self-fertilization of an $F_{2}$ plant, all alleles present in the offspring were derived from the same parent, and the $b$ value obtained from the parent-offspring regression is equal to heritability $(b=h)$. The heritability estimate was deduced as follows:

$$
h=\frac{V_{G}}{V_{p}} ; b=h ; b_{(F 2, F 3)}=\frac{\operatorname{COV}_{(F 2, F 3)}}{V_{F 2}}
$$

Where: $V_{G}=$ genetic variance; $V_{P}=$ phenotypic variance; $b_{(F 2, F 3)}=$ linear regression coefficient between the $F_{2}$ plant and the average number of days to heading of its $F_{3}$ family; $V_{F 2}=$ phenotypic variance of the $F_{2}$ generation. This variance was deduced from the genetic model of one locus and two alleles. Considering that the genotypes produced in the $F_{2}$ generation are represented by $A A, A a$, and $a a$, the genotypic frequency is equal to $\frac{1}{4}, \frac{1}{2}$, and $\frac{1}{4}$ and the genotypic value is equal to $+a, d$, and $-a$, respectively. Thus, it is possible to estimate the average $\left(A_{F 2}\right)$ and the phenotypic variance of the $F_{2}$ generation $\left(V_{F 2}\right)$ through the equations below, where $a=$ additive gene effect, $d=$ dominance gene effect, $V_{A}=$ additive variance, $V_{D}=$ dominance variance, and $V_{E}=$ environmental variance.

$$
\begin{gathered}
A_{F 2}=\frac{1}{4} a+\frac{1}{2} d+\frac{1}{4}(-a)=\frac{1}{2} d \\
V_{F 2}=\frac{1}{2} V_{A}+\frac{1}{4} V_{D}+V_{E}
\end{gathered}
$$

The covariance between an $\mathrm{F}_{2}$ plant and the average number of days to heading of its $\mathrm{F}_{3}$ family $\left(\mathrm{COV}_{(F 2, F 3)}\right)$ was also deduced from the model of one locus and two alleles, in which the genotypic frequency for $A A, A a$, and $a a$ is equal to $\frac{1}{4}$ ,$\frac{1}{2}$, and $\frac{1}{4}$ and the genotypic values is equal to $+a, \frac{1}{2} d$, and $-a$, respectively. Through the equations below, it is possible to estimate the average of the $F_{3}$ family $\left(A_{F 3}\right)$ and the covariance between an $F_{2}$ plant and its $F_{3}$ family $\left(\operatorname{COV}_{(F 2, F 3)}\right)$.

$$
\begin{gathered}
A_{F 3}=\frac{1}{4} a+\frac{1}{2}\left(\frac{1}{2} d\right)+\frac{1}{4}(-a)=\frac{1}{4} d \\
\operatorname{COV}_{(F 2, F 3)}=\frac{1}{2} V_{A}+\frac{1}{8} V_{D}
\end{gathered}
$$

The linear regression coefficient $(b)$ and heritability $(h)$ are now rewritten through the equation below. The equation shows that the largest fraction of the genetic variance consists of additive effects $\left(\frac{1}{2} a\right)$, while dominance effects, although present, are of smaller magnitude $\left(\frac{1}{8} d\right)$.

$$
b_{(F 2, F 3)}=h=\frac{\frac{1}{2} V_{A}+\frac{1}{8} V_{D}}{\frac{1}{2} V_{A}+\frac{1}{4} V_{D}+V_{E}}
$$

\section{RESULTS AND DISCUSSION}

\section{Phenotypic variation in heading date}

The frequency distribution of the number of days to heading for the URS Taura $\times$ Leggett population evaluated at the $F_{2}$ generation in 2015 is presented in Figure 1a. For this population, days to heading varied from 79 to 132 days among the $563 \mathrm{~F}_{2}$ individuals, and the average number of days to heading of the population was 100 days. The parents URS Taura and Leggett showed a great divergence in the average number of days to heading, with 81 and 122 days, 

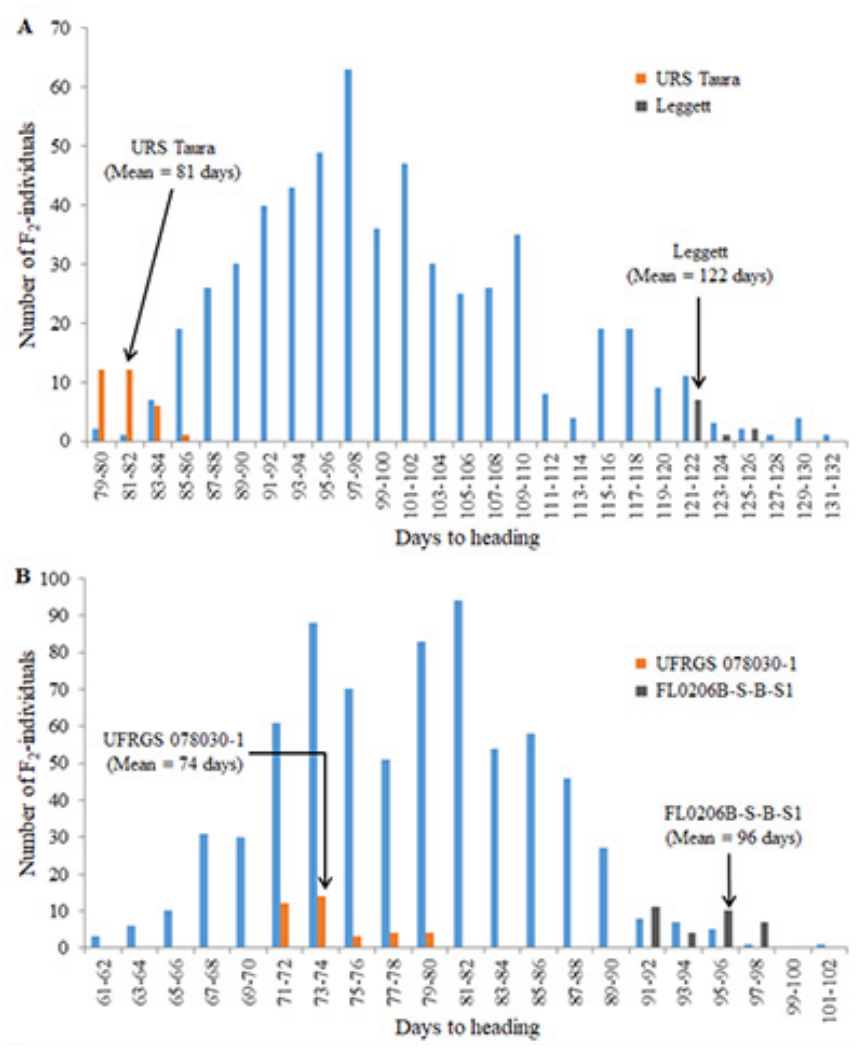

Figure 1. Frequency distribution of days to heading of the URS Taura $x$ Leggett (A) and FL0206B-S-B-S1 × UFRGS 078030-1 (B) oat populations evaluated at the $F_{2}$ generation in 2015. The means of parents grown adjacent to tests containing $F_{2}$ individuals are indicated with arrows. respectively. A range of variation of 53 days was observed among the $F_{2}$ individuals and 41 days between the parents (Table 1). The number of days to heading of the population evaluated at the $F_{3}$ generation in 2016 is presented in Figure 2a. The average number of days to heading varied from 76 to 120 days among the $74 F_{3}$ families and the overall average of the $F_{3}$ families was 92 days. For the parents URS Taura and Leggett, the average number of days to heading was 76 and 114 days, respectively. A range of variation of 44 days was observed among the $\mathrm{F}_{3}$ families exhibiting the shorter and longer vegetative cycle and 38 days between the parents (Table 1). On average, URS Taura presented a shorter time to heading compared to Leggett in both years, and the average number of days to heading at the $F_{2}$ and $F_{3}$ populations was midway between the phenotypes of the parents (Table 1).

The frequency distribution of the number of days to heading for the FL0206B-S-B-S1 x UFRGS 078030-1 population evaluated at the $F_{2}$ generation in 2015 is presented in Figure $1 \mathrm{~b}$. Days to heading varied from 61 to 102 days, showing a range of variation of 41 days among the $733 \mathrm{~F}_{2}$ individuals, with an average number of days to heading of the population of 79 days. The average number of days to heading was 96 and 74 days between FL0206B-S-B-S1 and UFRGS 078030-1, respectively, with a range of variation of 22 days between them (Table 1). The number of days to heading of the population

Table 1. Summary of phenotypic variation observed in heading date of the URS Taura $\times$ Leggett and FL0206B-S-B-S1 $\times$ UFRGS 078030-1 oat populations evaluated at the $\mathrm{F}_{2}$ and $\mathrm{F}_{3}$ generations

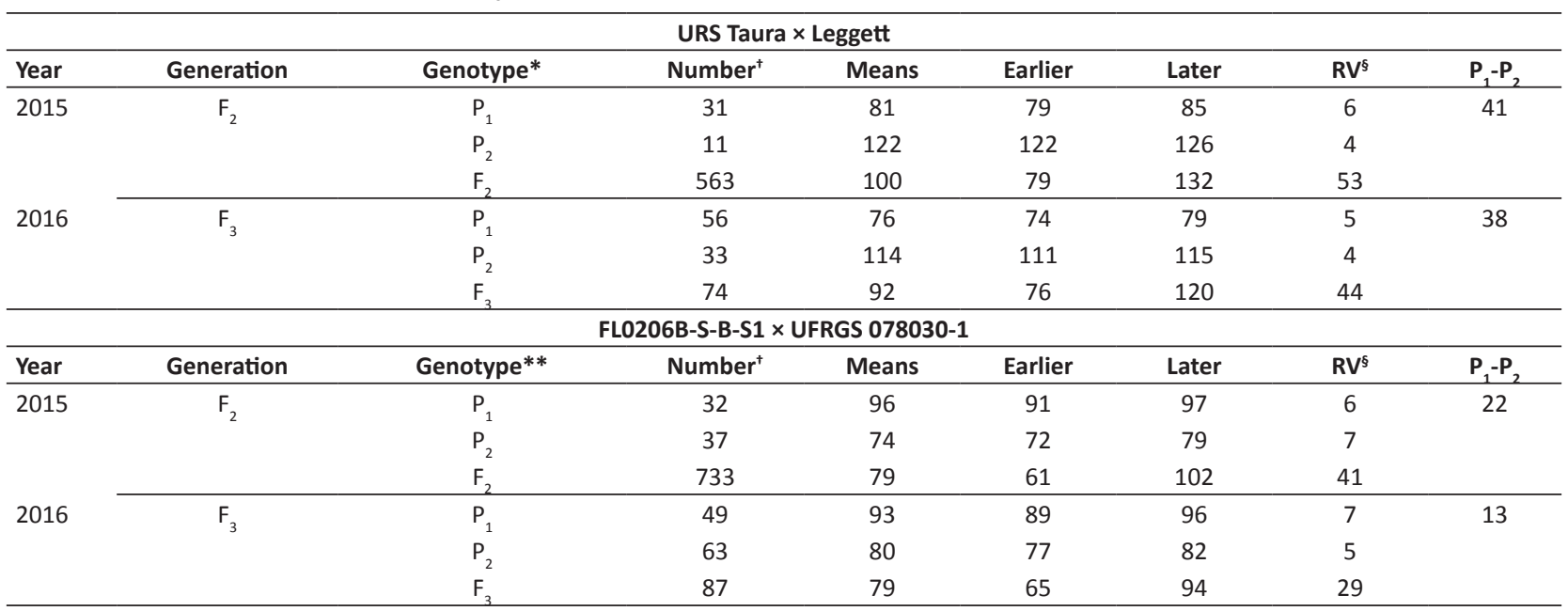

* For the population URS Taura $\times$ Leggett, $\mathrm{P}_{1}=$ URS Taura and $\mathrm{P}_{2}=$ Leggett.

** For the population FL0206B-S-B-S1 $\times$ UFRGS 078030-1, $\mathrm{P}_{1}=$ FL0206B-S-B-S1 and $\mathrm{P}_{2}=$ UFRGS 078030-1.

${ }^{+}$Number of individuals evaluated within each genotype class;

${ }^{\S}$ Range of variation between individuals with the lowest and highest average number of days to heading. 
evaluated at the $\mathrm{F}_{3}$ generation in 2016 is presented in Figure $2 \mathrm{~b}$. The average number of days to heading ranged from 65 to 94 days, displaying a range of variation of 29 days among the $87 \mathrm{~F}_{3}$ families and an overall average of 79 days. The average number of days to heading was 93 days for FL0206B-S-B-S1 and 80 days for UFRGS 078030-1, with a range of variation of 13 days between them (Table 1). On average, FL0206B-S-B-S1 showed a longer time to heading compared to UFRGS 078030-1 in both years of evaluation, while the average number of days to heading at the $F_{2}$ and $\mathrm{F}_{3}$ populations was the same and skewed towards the earlier parent UFRGS 078030-1 (Table 1).

A wide phenotypic variation in the number of days to heading was observed in the URS Taura $\times$ Leggett population. This phenotypic variation should reflect, at some level, the allelic differences between parents regarding the heading date trait. The cultivar URS Taura was released in 2009. It was developed from a simple cross between oat lines well-adapted to the sub-tropical environments, such as the ones found in Southern Brazil. In these environments, oat cultivars sensitive to the photoperiod and vernalization may mature too late, making harvesting before the optimal planting date of the succeeding crop (usually soybean) difficult and therefore, unattractive to farmers (Locatelli et al. 2007). Thus, it is likely that in its genome URS Taura possesses alleles related to insensitivity to both photoperiod and vernalization.

On the contrary, Leggett is a well-adapted cultivar in all areas of western Canada, where the period from sowing to harvesting is fairly short (April/May to July/August). In these environments, oat plants are exposed to a photoperiod favorable to the occurrence of flowering from the early stages of development, and the most adapted cultivars are those carrying alleles that induce flowering under long day-lengths. Therefore, alleles related to the sensitivity to photoperiod and insensitive to vernalization must be present in the Leggett's genome. When Leggett was evaluated in experiments carried out in black soil and the climate of Manitoba and Saskatchewan, Canada, the average time to flowering was 57 days (Fetch et al. 2007). In the present study, where the photoperiod was not favorable to flowering during the whole plant growth cycle, the average time doubled in both years of field tests (Table 1 ). In small grain cereals such as wheat and barley, the $P p d-1$ gene plays a central role in the regulation of the sensitivity to the photoperiod (Nishida et al. 2013, Pearce et al. 2017). In these species, $P p d-1$ accelerates flowering under long days by the positive regulation of the Vrn3 gene, which is a promoter of flowering time and integrates responses to photoperiod, temperature, and vernalization (Turner et al. 2005). Mutant wheat genotypes for the Ppd-1 gene showed early flowering under long- and short-day conditions, demonstrating their insensitivity to photoperiod (Beales et al. 2007). Future studies, including the cloning and sequencing of the $P p d-1$ gene in oat, could elucidate whether structural variations within the coding regions of the gene are associated with differences in the response to photoperiod observed in many genotypes, such as Leggett and FL0206B-S-B-S1.
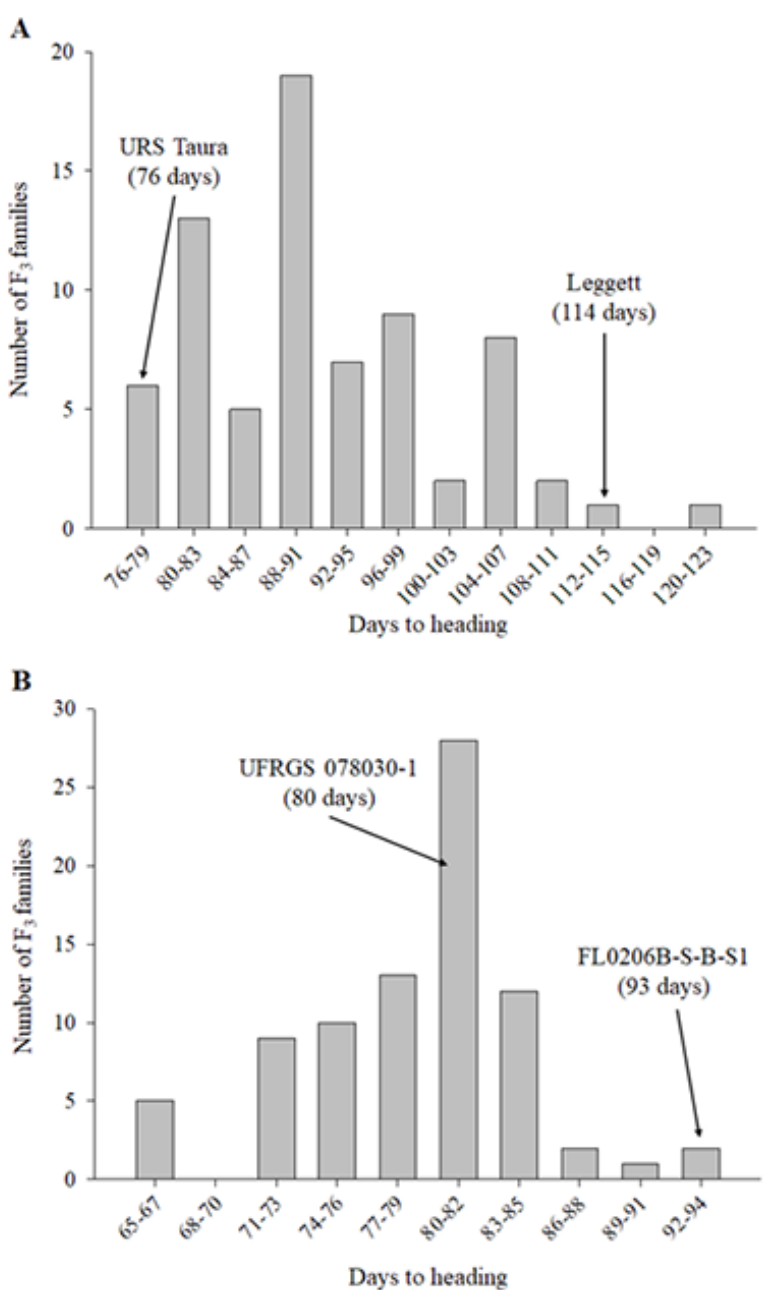

Figure 2. Frequency distribution of days to heading of the URS Taura $\times$ Leggett (A) and FL0206B-S-B-S1 $\times$ UFRGS 078030-1 (B) oat populations evaluated at the $F_{3}$ generation in 2016. The means of parents grown adjacent to tests containing $F_{3}$ families are indicated with arrows. 
For the 'FL0206B-S-B-S1 $\times$ UFRGS 078030-1' population, the phenotypic variation observed in heading date among the $F_{2}$ individuals and $F_{3}$ families also represents differences in the genetic background of the parents. In this case, FL0206B-S-B-S1 is highly adapted to environments in the southern United States, where the photoperiod is favorable to flowering from the early stages of plants' development. It is expected that FL0206B-S-B-S1 possesses alleles related to the sensitivity to photoperiod and insensitivity to vernalization. However, the sensitivity to photoperiod observed in FL0206B-S-B-S1 was less intense than the sensitivity observed in Leggett. In all the experiments carried out in the present study, FL0206B-S-B-S1 showed an earlier heading phenotype compared to Leggett, suggesting that these parents must have different genes or different alleles of the same genes in response to photoperiod. It is important to highlight that FL0206B-S-B-S1 carries in its genealogy information from a parent (UFRGS 995088-3) developed in Brazil, which may substantially contribute to the lower sensitivity to photoperiod and the greater agronomic adaptation in the growing environments of Southern Brazil. The UFRGS 078030-1 parent stands out for its early flowering phenotype, which indicated that it must carry alleles related to the insensitivity to both photoperiod and vernalization and alleles of earliness per se in its genome.

The phenotypic results obtained in this study for the URS Taura $\times$ Leggett population clearly demonstrate that heading date was shorter in 2016 than in 2015 in the evaluated progenies $\left(F_{2}\right.$ and $\left.F_{3}\right)$ and parents (Table 1). Plants are highly sensitive to temperature and can perceive differences as little low as $1{ }^{\circ} \mathrm{C}$ (Kumar and Wigge 2010). Maximum daily temperatures were higher in 2016 than in 2015 (data not presented), indicating that differences in the number of days to heading over the two years may reflect variations in temperature between the years. However, it is important to understand how temperature is sensed and integrated into the development of plants. Although knowledge regarding the thermosensory response among crop species is very limited, the acceleration of flowering in response to higher temperatures in Arabidopsis thaliana depends on the increased expression of the FT (FLOWERING LOCUS T) gene, a homologue of the Vrn3 gene in wheat and barley and the PIF (PHYTOCHROME INTERACTING FACTOR) gene family (Kumar and Wigge 2010, Capovilla et al. 2014). For the FL0206B-S-B-S1 $\times$ UFRGS 078030-1 population, the downward trend in the time to heading in 2016 compared to 2015 was not so clearly observed. The parent UFRGS 078030-1 presented an opposite phenotypic pattern, in which time to heading was reduced in 2015 (Table 1). Still, the average number of days to heading of the progenies $\left(\mathrm{F}_{2}\right.$ and $\left.\mathrm{F}_{3}\right)$ did not change between years. These results support the hypothesis that UFRGS 078030-1 possess alleles of earliness per se, which may be associated with insensitivity to temperature since increases in temperature did not decrease the number of days to heading among the assessed progenies of this population.

\section{Heritability of the heading date}

The heritability of the heading date trait was estimated in the URS Taura $\times$ Leggett and FL0206B-S-B-S1 $x$ UFRGS 078030-1 oat populations. A heritability coefficient $(h)$ of 0.68 and 0.46 was estimated for the URS Taura $\times$ Leggett and FL0206B-S-B-S1 $\times$ UFRGS 078030-1 populations, respectively (Figure 3 ). In both populations, the heritability $(h)$ values were obtained from the linear regression coefficient $(h)$. For the URS Taura $\times$ Leggett population, the standard error of the regression slope, which represents the average distance that the observed data departs from the regression line, was 0.0866 . The $99 \%$ confidence interval for the slope of the regression line was $0.68 \pm 0.23(0.45-0.91)$. For the FL0206BS-B-S1 $\times$ UFRGS 078030-1 population, the standard error of the regression slope was 0.0504 , while the $99 \%$ confidence interval for the slope of the regression line was $0.46 \pm 013(0.33-0.59)$. The small standard error estimated in this study for both populations indicates that the observations are close to the fitted line. A coefficient of determination of 0.46 and 0.49 was estimated for the URS Taura $\times$ Leggett and FL0206B-S-B-S1 $\times$ UFRGS 078030-1 populations, respectively (Figure 3).

Although the genetic components defined by the covariance of parents and offspring $\left(\mathrm{COV}_{(F 2, F 3)}\right)$ include additive and dominance effects, a close estimate of 'narrow-sense heritability' was obtained in the present study. The covariance of parents and offspring consists of $\frac{1}{2} V_{A}$ and $\frac{1}{8} V_{D}$, indicating that the additive component had a greater effect on the heritability estimates than the dominance in both populations. Based on this assumption, the phenotypic results can be reliably employed to predict what is effectively transmitted from one generation to another (breeding value), allowing the prediction of the response to selection for the heading date trait in the evaluated oat populations.

The highest value of heritability obtained in URS Taura $\times$ Leggett compared to FL0206B-S-B-S1 $\times$ UFRGS 078030-1 should be in line to the expected level of genetic distance between the two populations. Based on the parental genealogy 
information, FL0206B-S-B-S1 and UFRGS 078030-1 are more genetically related than URS Taura and Leggett. The genetic distance between URS Taura and Leggett must have contributed to inflate the genetic variance in the population and therefore, the heritability estimate. The heritability values estimated in this study suggest intermediate genetic and environmental effects over the phenotypic expression of heading date. Heritability of heading date in hexaploid oat has already been estimated in previous studies. Nava et al. (2010) estimated a heritability coefficient of 0.89 in a population of fixed/pure oat lines. The estimate was based on the average of homozygous lines evaluated at one location with three replicates. Through analysis of variance, the components of the total phenotypic variance were partitioned into genetic and environmental variances, and broad-sense heritability was estimated.

The development of cultivars showing high grain yield potential, industrial yield, resistance to disease, and favorable vegetative cycle, among other traits, represent important objectives for oat breeding programs. One of the fundamental bases of crop improvement is the existence of inheritable variation in traits of agronomic interest within the breeding populations. In the present study, a wide phenotypic variation was observed in heading date in both populations. Naturally, a fraction of this variation can be directly attributed to environmental (non-genetic) factors. However, the segregation patterns clearly demonstrate the existence of allelic differences between parents of each population, which significantly contributed to the occurrence of distinct phenotypic groups among the assessed progenies. These differences represent a great opportunity to select oat genotypes adapted to the most diverse growing areas in Brazil and abroad. In contrast, the heritability estimates indicate that the response to selection for heading date in oat may occur relatively slowly in early generations of selffertilization. More expressive genetic gains could be achieved through combined selection strategies based on phenotype and genotype through molecular marker-assisted selection mapping, and regulation of genes controlling the key pathways of flowering time in oat will be essential. It is expected that these studies will advance our understanding of the genetic basis of this adaptive trait and the development of increasingly productive oat cultivars.

\section{REFERENCES}

Beales J, Turner A, Griffith S, Snape JW and Laurie DA (2007) A pseudoresponse regulator is misexpressed in the photoperiod insensitive Ppd-D1a mutant of wheat (Triticum aestivum L.). Theoretical and Applied Genetics 115: 721-733.

Capovilla G, Schmid M and Posé D (2014) Control of flowering by ambient temperature. Journal of Experimental Botany 64: 3273-3284.
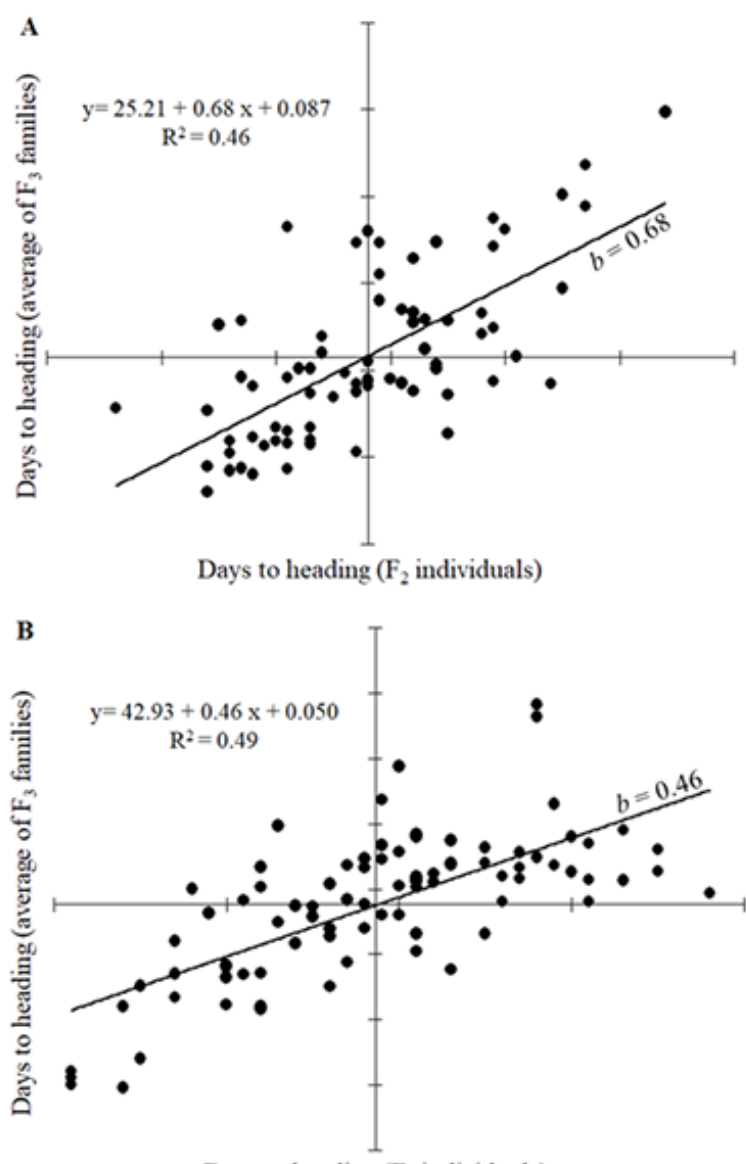

Days to heading ( $\mathrm{F}_{2}$ individuals)

Figure 3. Offspring-parent regression used to estimate the heritability of heading date in the URS Taura $\times$ Leggett $(A)$ and FL0206B-S-B-S1 $\times$ UFRGS 078030 (B) oat populations. The linear regression model is $Y i=a+b X i+e i$, where $Y i=$ performance of offspring of the ith parent, $a=$ mean performance of all parents evaluated, $b=$ linear regression coefficient, $X i=$ performance of $i$ th parent, and $e i=$ standard error associated with measurement of $X i$ (standard error of regression slope). 
Phenotypic variation and heritability of heading date in hexaploid oat

Falconer DS and Mackay TFC (1996) Introduction to quantitative genetics. $4^{\text {th }}$ edn, Essex, Longman, 464p.

FAOSTAT - Food and Agriculture Organization of the United Nations (2019) Food and agriculture data. Available at <http://www.fao.org/ faostat>. Accessed on April 18, 2019.

Fetch JWM, Duguid SD, Brown PD, Chong J, Fetch TG, Haber SM, Menzies JG, Mes N, Noll J, Aung T and Stadnyck KD (2007) Leggett oat. Canadian Journal of Plant Science 87: 509-512.

Kippes N, Chen A, Zhang X, Lukaszewski AJ and Dubcovsky J (2016) Development and characterization of a spring hexaploid wheat line with no functional VRN2 genes. Theoretical and Applied Genetics 129: $1417-1428$.

Klos KE, Huang YF, Bekele WA, Obert DE, Babiker E, Beattie AD, Bjornstad A, Bonman JM, Carson ML, Chao S, Gnanesh BN, Griffithd I, Harrison SA, Howarth CJ, Hu G, Ibrahim A, Islamovic E, Jackson EW, Jannick JL, Kolb FL, McMullen MS, Fetch JWM, Murphy JP, Ohm HW, Rines HW, Rossnagel BG, Schlueter JA, Sorrells ME, Wight CP, Yan W and Tinker NA (2016) Population genomics related to adaptation in elite oat germplasm. Plant Genome 9: 1-12.

Kumar SV and Wigge PA (2010) H2A.Z-containing nucleosomes mediate the thermosensory response in Arabidopsis. Cell 140: 136-140.

Locatelli AB, Federizzi LC, Milach SCK and McElroy AR (2007) Flowering time in oat: genotype characterization for photoperiod and vernalization response. Field Crops Research 106: 242-247.

Locatelli AB, Federizzi LC, Milach SCK, Wight CP, Molnar SJ, Chapados JT and Tinker NA (2006) Loci affecting flowering time in oat under short-day conditions. Genome 49: 1528-1538.

Nava IC, Duare ITL, Pacheco MT and Federizzi LC (2010) Genetic control of agronomic traits in an oat population of recombinant line. Crop Breeding and Applied Biotechnology 10: 305-311.

Nava IC, Wight CP, Pacheco MT, Federizzi LC and Tinker NA (2012) Tagging and mapping candidate loci for vernalization and flower initiation in hexaploid oat. Molecular Breeding 30: 1295-1312.

Nishida H, Yoshida T, Kawakami K, Fujita M, Long B, Akashi Y, Laurie DA and Kato $K$ (2013) Structural variation in the $5^{\prime}$ upstream region of photoperiod-insensitive alleles $P p d-A 1 a$ and $P p d-B 1 a$ identified in hexaploid wheat (Triticum aestivum L.), and their effect on heading time. Molecular Breeding 31: 27-37.

Pearce S, Shaw LS, Lin H, Cotter JD, Li C and Dubcovsky J (2017) Night-break experiments shed light on the photoperiod1-mediated flowering. Plant Physiology 174: 1139-1150.

Sorrells ME and Simmons SR (1992) Influence of environment on the development and adaptation of oat. In Marshal HG and Sorrells ME (eds) Oat science and technology. The American Society of Agronomy, Wisconsin, p. 115-163.

Turner A, Beales J, Faure S, Dunford RP and Laurie DA (2005) The pseudoresponse regulator $\mathrm{Ppd}-\mathrm{H} 1$ provides adaptation to photoperiod in barley. Science 11: 1031-1034.

Würschum T, Langer SM, Longin CFH, Tucker MR and Leiser WL (2018) A three-component system incorporating $P p d-D 1$, copy number variation at $P p d-B 1$, and numerous small-effect QTL facilitates adaptation of heading time in winter wheat cultivars of worldwide origin. Plant, Cell \& Environment 41: 1407-1416.

Zikhali M, Wingen LU and Griffiths S (2016) Delimitation of the Earliness per se D1 (Eps-D1) flowering gene to a subtelomeric chromosomal deletion in bread wheat (Triticum aestivum). Journal of Experimental Botany 67: 287-299. 